\title{
Outcome of a risk-related therapeutic strategy used prospectively in a population-based study of Hodgkin's lymphoma in adolescents
}

\author{
GL Jones', PRA Taylor', KP Windebank ${ }^{2}$, NA Hoye ${ }^{3}$, H Lucraft ${ }^{4}$, K Wood', B Angus' and SJ Proctor $^{*, 5}$ \\ 'Newcastle upon Tyne NHS Foundation Trust, Newcastle upon Tyne NEI 4LP, UK; ${ }^{2}$ Paediatric Oncology, Newcastle upon Tyne NHS Foundation Trust, \\ Newcastle upon Tyne NEI 4LP, UK; ${ }^{3}$ Northumbria Healthcare NHS Trust, North Shields Tyne \& WearNE29 8NH, UK; ${ }^{4}$ Northern Centre for Cancer \\ Treatment, Newcastle upon Tyne NHS Foundation Trust, Newcastle upon Tyne NE4 6BE, UK; ${ }^{5}$ Academic Haematology, Medical School, Newcastle \\ University, Newcastle upon Tyne NE2 4HH, UK
}

The aim was to assess outcome in a population-based cohort of adolescents with Hodgkin's lymphoma (HL) diagnosed in the UK's northern region over a 10 -year period. Among a population of 3.09 million, 55 of 676 patients (8\%) diagnosed with $\mathrm{HL}$ were aged 13- 19. Seven had nodular lymphocyte-predominant HL, 48 classical HL (cHL). Of the latter, 36 were $\geqslant 16$ years. Application of the Scottish and Newcastle Lymphoma Group (SNLG) prognostic index meant 21 patients were considered high risk (index $\geqslant 0.5$ ). They received PVACEBOP multi-agent chemotherapy as primary therapy. Standard risk patients (SNLG index $<0.5)$ were treated with standard ChIVPP or ABVD chemotherapy \pm radiotherapy. Scottish and Newcastle Lymphoma Group indexing is not valid for patients under 16. Twelve patients therefore received UKCCSG protocols $(n=8)$, ABVD plus radiotherapy $(n=2)$, or PVACEBOP $(n=2)$. Forty-six patients with $\mathrm{cHL}(96 \%)$ achieved complete remission. Seven patients relapsed but all entered complete remission after salvage therapy. Five patients died: three of $\mathrm{HL}$, one in an accident and one of disseminated varicella complicating cystic fibrosis. Five- and I0-year overall survival was 93 and 86\%, respectively; disease-specific survival was 95 and 92\%. The data suggest that older adolescents with high-risk $\mathrm{HL}$ require intensive protocols as primary therapy to secure optimal outcome.

British Journal of Cancer (2007) 97, 29-36. doi:I0.1038/sj.bjc.6603809 www.bjcancer.com

Published online 29 May 2007

(c) 2007 Cancer Research UK

Keywords: Hodgkin lymphoma; adolescent; population study; chemotherapy

Hodgkin's lymphoma (HL) is a rare malignancy, with an incidence of approximately 2.4 per 100000 per annum in developed countries. In these countries, the incidence of the disease is very low in young children, peaks in young adults, wanes in middle age then gradually increases again over the later decades (Kennedy et al, 1985; Armstrong et al, 1994). During the teenage years there is a steep rise in the incidence of HL, culminating in the peak incidence described in the third decade. There is increasing circumstantial evidence that HL in young children may be the result of a different pathological process to that occurring in young adults.

One potentially significant observation is that HL in young children is more clearly Epstein-Barr virus (EBV) associated than in young adults. This may be important as there is increasing evidence to suggest that the EBV status of tumour cells in HL has an impact on prognosis. This effect may, however, be age dependent (Jarrett et al, 2005; Keegan et al, 2005), although these observations have not been replicated in all studies (Jarrett et al, 2005).

Differences in histological subtype of HL in different age cohorts may also be important. While in children, as in adults, the nodular sclerosing (NS) subtype predominates, up to $30 \%$ may have mixed cellularity (MC) disease. Among 17-20 year olds, however, the

*Correspondence: Professor SJ Proctor; E-mail: s.j.proctor@ncl.ac.uk Received 27 February 2007; revised 24 April 2007; accepted 26 April 2007; published online 29 May 2007 incidence of MC disease is lower, affecting as few as $4 \%$ of individuals in some studies.

Thus, it could be argued that adolescents as a group are susceptible to both young adult-type and childhood-type HL, or alternatively, that they may actually represent a unique cohort with respect to the epidemiology, pathophysiology and potentially prognosis of HL (Windebank, 2005).

In addition to the heterogeneous biological features of $\mathrm{HL}$ presenting during the teenage years, it is pertinent to consider the treatments and modes of treatment delivery to this group of patients in the UK. The multidisciplinary team responsible for the management of teenagers with HL varies and is dependent upon local healthcare configurations. In many regions, patients aged $>16$ years are treated by adult haematologists or oncologists at local hospitals, while those aged $<16$ years are managed by paediatric oncology teams, generally at regional centres. More recently, in some areas, patients are being treated on designated teenage cancer units either by paediatric or adult teams. It is unsurprising, therefore, that there are considerable variations in the therapeutic regimens used in the management of these patients; while some patients are treated using regimens primarily designed for children (Jenkin et al, 1982; Ekert et al, 1988; Hudson et al, 1993; Hunger et al, 1994; Shankar et al, 1997, 1998; Weiner et al, 1997; Hutchinson et al, 1998; Schellong et al, 1999; Landmann-Parker et al, 2000), others are managed using adulttype approaches (Proctor et al, 1991; Yung et al, 2004). 
A To calculate the index the patient's age, clinical stage, absolute lymphocyte count, haemoglobin and bulk disease are required.

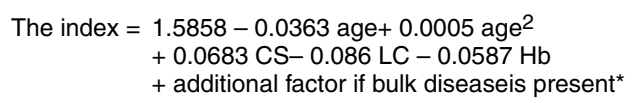

Age is entered as an absolute figure in the equation

Clinical stage entered according to the key (Ann Arbor classification)

$\begin{array}{ll}\text { IA, IIA, IIIA } & =1 \\ \text { IB, IIB } & =2 \\ \text { IIIB } & =3 \\ \text { IV } & =4\end{array}$

Absolute lymphocyte count is entered as a score

$$
\begin{array}{ll}
<1.0 \times 10^{9} \mathrm{I}^{-1} & =1 \\
1.0-1.5 \times 10^{9} \mathrm{I}^{-1} & =2 \\
1.5-2.0 \times 10^{9} \mathrm{I}^{-1} & =3 \\
>2.0 \times 10^{9} \mathrm{I}^{-1} & =4
\end{array}
$$

Haemoglobin $(\mathrm{Hb})$ in $\mathrm{g} \mathrm{dl}^{-1}$ is entered as an absolute figure in equation

${ }^{*}$ Bulk disease (a single node of $\geqslant 5 \mathrm{~cm}$ ) or $\geqslant 30 \%$ of intrathoracic ratio add to index factor of 0.3

A total index score of $\geqslant 0.5$ was the criteria for regarding patient as poor risk.

There is an on-line programme for calculation of the index at www.shieldstudy.co.uk

Male sex

2) Clinical Stages 2B, 3B and 4

3) Bulky mediastinum

4) Leukocytosis $\left(\mathrm{WBC}>13.5 \times 103 \mathrm{~mm}^{-3}\right.$

5) Anaemia $(\mathrm{Hb}<11 \mathrm{~g})$

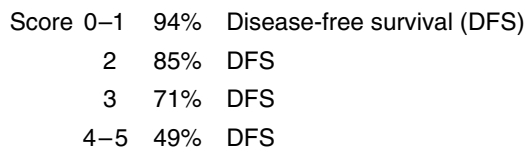

Figure I (A) Scottish and Newcastle Lymphoma Group prognostic index for Hodgkin's disease risk evaluation. (B) Prognostic index for childhood HD risk evaluation (Smith et al, 2003).

Since 1991, patients aged 13-19 years and all adults diagnosed with HL in the Northern Region of England, have been prospectively managed using a risk-adapted treatment approach. The Scotland and Newcastle Lymphoma Group (SNLG) prognostic index (Figure 1A), proven to be of value in identifying high-risk patients >15years old (Proctor et al, 1991), has been used to determine whether patients would benefit from intensified treatment. For those too young for valid use of the SNLG index, poor risk status was assigned to those with high-stage and very bulky or extensive extra-nodal disease - factors later confirmed to be of significance by Smith et al, 2003 (Figure 1B). Although patients were managed by a mixture of adult physicians and paediatricians, the overall therapeutic strategy was consistent, with the use of a common intensified protocol for the poor risk patients identified either clinically or by the index. We present the results of this treatment strategy.

\section{PATIENTS AND METHODS}

The Northern Region Lymphoma Group (NRLG) collected data prospectively on all patients diagnosed with HL in the Northern region of England, as previously described (Taylor et al, 1998; Proctor et al, 2002). In addition, the Northern Region Young Person's Malignancy Registry (NRYPMR) collects data at presentation from all patients, aged $\leqslant 25$ years diagnosed with a malignant disease in the same geographical area (Cotterill et al, 2000). Patients were included in the present study if they presented between 1 January 1991 and 31 December 2000 with histologically confirmed, newly diagnosed HL, were aged 13-19 years (inclusive) at diagnosis and were normally resident in the area at the time of diagnosis. Histological material from all patients was centrally reviewed prior to patient inclusion on the register as previously described (Taylor et al, 1998).

\section{Registration and follow-up}

The following data were collected from each patient at the time of registration: age, sex, histological subtype, full blood count, clinical stage at presentation, presence or absence of bulk disease, presence or absence of B-symptoms and first-line treatment modality. Level of haemoglobin, absolute lymphocyte count, age, stage and bulk disease assessment were required to calculate the SNLG index (Proctor et al, 1991).

Follow-up data regarding attainment of remission, relapse, requirement for second-line and subsequent therapy, date of death and cause of death were obtained from treating physicians or casenote review. Follow-up was to June 2005, or the date that the patient was last known to be alive. Data collection and analysis were undertaken with approval of the local ethical committee.

\section{Treatment strategy}

Patients aged 16-19 years were managed using a risk-adapted strategy based on the SNLG prognostic index (Proctor et al, 1991).

High-risk patients Patients identified as high risk were eligible for the SNLG-HD III trial protocol (Proctor et al, 2002), which involved treatment with three consecutive 28-day cycles of an eight-drug regimen (PVACEBOP: procarbazine, vinblastine, dox- 
orubicin, chlorambucil, etoposide, bleomycin, vincristine and prednisolone; Table 1a). This was followed by involved-field radiotherapy (RT) to residual masses or sites of original bulk disease. Patients who gained a complete remission (CR) or good partial remission (GPR) were then randomised between two further cycles of PVACEBOP chemotherapy, or an autologous haemopoietic stem cell transplant (HSCT) with etoposide and melphalan preconditioning. High-risk patients who did not consent to trial entry were allowed to have this chemotherapy treatment off-study. Patients who relapsed or failed to remit were treated with the salvage chemotherapy regimen IVE (ifosfamide, etoposide (VP16) and epirubicin; Table 1b) and an autologous HSCT. After PVACEBOP, mobilisation of stem cells can be problematic if five courses have been used; so marrow harvest will be required for autograft in such circumstances. Relapse after PVACEPOP in this cohort was a rare event, so this was not a practical problem.

Table I PVACE BOP primary therapy for poor-risk cases (SNLG index $>0.5)$

\begin{tabular}{|c|c|}
\hline \multicolumn{2}{|c|}{ (a) For high-risk Hodgkin's disease } \\
\hline Day I & Vinblastine $\left(6 \mathrm{mg} \mathrm{m}^{-2} \mathrm{IV}\right)$ \\
\hline Day I-3 & $\begin{array}{l}\text { Etoposide (IV } 100 \mathrm{mg} \mathrm{m}^{-2} \times 1 \text { dose) } \\
\text { Oral (200 } \mathrm{mg} \mathrm{m}^{-2} \times 2 \text { doses) }\end{array}$ \\
\hline Days $1-14$ & Procarbazine ( $100 \mathrm{mg} \mathrm{m}^{-2}$ oral) \\
\hline Days $1-14$ & Chlorambucil ( $6 \mathrm{mg} \mathrm{m}^{-2}$ oral) \\
\hline Day 8 & Adriamycin $\left(25 \mathrm{mg} \mathrm{m}^{-2} \mathrm{IV}\right)$ \\
\hline Day 8 & Vincristine $(2 \mathrm{mg} / \mathrm{V})$ \\
\hline Day 15 & Bleomycin $\left(6 \mathrm{mg} \mathrm{m}^{-2} \mathrm{IV}\right)$ \\
\hline ay 22 & Bleomycin $\left(6 \mathrm{mg} \mathrm{m}^{-2} \mathrm{IV}\right)$ \\
\hline Days $14-28$ & $\begin{array}{l}\text { Prednisolone } \\
\text { ( } 40 \mathrm{mg} \text { daily oral) }\end{array}$ \\
\hline & $=$ Day I of next course \\
\hline
\end{tabular}

(b) Ifosphamide, VPI 6 and epirubicin (IVE) for relapsed or progressive Hodgkin's disease

VPI6 $\quad 200 \mathrm{mg} \mathrm{m}^{-2} \mathrm{day}^{-1}$ as $2 \mathrm{~h}$ infusion days I -3

Epirubicin $\quad 50 \mathrm{mg} \mathrm{m}^{-2}$ day $^{-1} \mathrm{IV}$ day I (bolus)

Ifosphamide $\quad 3 \mathrm{~g} \mathrm{~m}^{-2} 24 \mathrm{~h}$ infusions days I -3 with MESNA cover in 2.5 | dextrose saline

Abbreviations: IV, intravenously; IVE, ifosfamide, etoposide (VPI6) and epirubicin; PVACEBOP, procarbazine, vinblastine, doxorubicin, chlorambucil, etoposide, bleomycin, vincristine and prednisolone; SNLG, Scottish and Newcastle Lymphoma Group. Bleomycin omitted from cycles 4 and 5 if patients have had mantle/ mediastinal radiotherapy. A $100 \mathrm{mg}$ hydrocortisone IV administered with bleomycin. Septrin $(960 \mathrm{mg})$, once daily, should be given throughout treatment on Mondays, Wednesdays and Fridays. On day I of each cycle before ifosphamide is administered a loading dose of $1.8 \mathrm{gm}^{-2}$ of MESNA is given as an IV bolus. A final infusion of MESNA $5.4 \mathrm{~g} / \mathrm{m}^{2}$ ( $60 \%$ of total ifosphamide dose) will be given in $1.5 \mathrm{I}$ of dextrose saline given over $12 \mathrm{~h}$. Three cycles, at 21 -day intervals (neutrophils $>1.5 \times 10 / 9 / 1$ and platelets $>75 \times 10 / 9 / 1)$ for a total of three courses. Patients receive phenytoin (po $300 \mathrm{mg}$ ) daily from days $\mathrm{I}-5$.
Standard risk patients Patients with SNLG index $<0.5$ were treated according to Northern Region Haematology Guidelines. Early stage 1A and 2A patients received three courses of ChlVPP (chlorambucil, vinblastine, procarbazine and prednisolone) or ABVD (doxorubicin, bleomycin, vinblastine and dacarbazine) and involved-field RT to sites of residual or initial bulk disease. Before 1994, extended-field RT was used alone as primary therapy. Patients with higher-stage disease were treated with a minimum of six courses of a four-drug schedule (ChlVPP or ABVD) and involved-field RT.

\section{Survival analysis}

Since (NLPHL) is now regarded as a subtype of low-grade non-HL, patients with this disease subtype have been analysed separately. Overall survival (OS) was measured from the date of diagnosis until the date of death. Disease-specific survival (DSS) was measured after censoring the data for deaths unrelated to HL. Event-free survival (EFS) was calculated from date of diagnosis to failure to achieve remission, relapse, disease progression, death or last follow-up.

\section{Statistical analysis}

Prism 4.0 (GRAPHPAD Software, San Diego, CA, USA) was used for data analysis. Actuarial survival curves were compiled using the Kaplan-Meier method (Kaplan and Meier, 1958). The log-rank test was used to compare curves. Fisher's exact test was used where appropriate.

\section{RESULTS}

\section{Patient characteristics}

The former Northern Region of England has a population of 3.09 million. Over the 10 years of the study, 676 individuals presented with histologically confirmed HL, of whom $55(8 \%)$ were aged 13 19 years at diagnosis. Of these, 48 patients ( 27 males, 21 females) had classical HL (cHL) and seven (six males, one female) had NLPHL. Median follow-up was 107 months (range 32-165) for surviving patients. The clinical characteristics of the patients and their outcomes during follow-up are shown in Tables $2 a$ and $b$.

\section{Classical HL (cHL)}

Therapy and outcome Of the 48 patients in this group, 36 were aged $\geqslant 16$ years and were thus eligible for assessment using the SNLG index, and 12 were aged $<16$ years; application of the SNLG was not valid for this group. Outcomes by therapeutic modality and age are shown in Figure 2. In all, 46 of 48 patients (96\%) achieved a remission after first-line therapy. Both primary

Table 2 Clinical features and outcome of the cohort

\begin{tabular}{|c|c|c|c|c|c|c|c|c|c|c|c|c|c|c|c|c|c|c|c|}
\hline \multirow[b]{2}{*}{ Age } & \multicolumn{2}{|c|}{ Gender } & \multicolumn{8}{|c|}{ Clinical stage } & \multicolumn{2}{|c|}{ Pathology } & \multicolumn{2}{|c|}{ SNLG index } & \multicolumn{3}{|c|}{ Smith index } & \multirow[b]{2}{*}{5 year DSS } & \multirow[b]{2}{*}{5 year EFS } \\
\hline & $\mathbf{M} / \mathbf{F}$ & IA & IB & IIA & IIB & IIIA & IIIB & IVA & IVB & NS & MC & $<0.5$ & $\geqslant 0.5$ & $0 / 1$ & 2 & 3 & $4 / 5$ & & \\
\hline \multicolumn{2}{|c|}{ Gender } & \multicolumn{8}{|c|}{ Clinical stage } & \multicolumn{3}{|c|}{ SNLG index } & \multicolumn{3}{|c|}{ Smith index } & & & & \\
\hline
\end{tabular}

(b) Lymphocyte-predominant HL

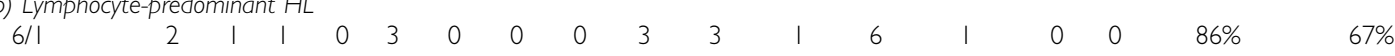

Abbreviations: DSS, disease-specific survival; EFS, event-free survival; HL, Hodgkin's lymphoma; SNLG, Scottish and Newcastle Lymphoma Group. 
refractory patients died of HL despite the use of high-dose salvage chemotherapy. Seven patients relapsed after primary therapy, three of these patients received radiotherapy alone as first-line treatment. All patients re-entered remission after salvage chemotherapy, but one subsequently died of HL. Two patients died of causes unrelated to HL; one died in a road traffic accident (RTA) and one (who also had cystic fibrosis) died of disseminated varicella zoster infection 96 months after presentation while in first $\mathrm{CR}$. The 5-year and 10-year OS for this cohort was 93 and $86 \%$, respectively (Figure 3A). DSS rates were 95 and 92\% (Figure 3B).

Twenty-one patients, regarded as having high-risk disease, were treated using the PVACEBOP regimen (Table 1a). Of these, five patients received chemotherapy alone, 16 received combined therapy and four had an autologous transplantation in CR1 as part of the SNLG-HD III trial. With respect to SNLG prognostic index, 19 patients were aged $\geqslant 16$ years and 17 of 19 had an SNLG index $\geqslant 0.5$, thus reaching the criteria for high-risk disease. Two other patients with SNLG scores $<0.5$ were treated using the highrisk protocol at the discretion of the treating physician. Both are well in first CR and have experienced no late effects to date. Two patients, aged 13 and 15 years, were also treated using this protocol because of clinical poor risk profile with massive mediastinal disease. There were two primary refractory patients, who subsequently died of their disease, and one patient with a highSNLG index entered CR but relapsed on several occasions, and died of progressive disease despite a reduced-intensity sibling HSCT.

Nineteen patients were treated using four-drug regimens (Figure 2). Combined chemotherapy and radiotherapy was used as first-line therapy in 11 cases, and chemotherapy was used alone in eight cases. All patients achieved CR. All patients treated in this group were considered to have standard risk disease, with one exception; a patient with a high-SNLG score was treated using this protocol, as she could not tolerate oral medication. She relapsed 12 months after diagnosis and was salvaged with IVE followed by an autologous HSCT. Another patient relapsed but was also alive in CR2 after salvage chemotherapy and an autologous HSCT. This patient's primary therapy was considered suboptimal as she became pregnant after two courses of chemotherapy and deferred further treatment until the postnatal period.

Eight patients with localised disease were managed with radiotherapy alone as first line-therapy (Figure 2). Five of these

A
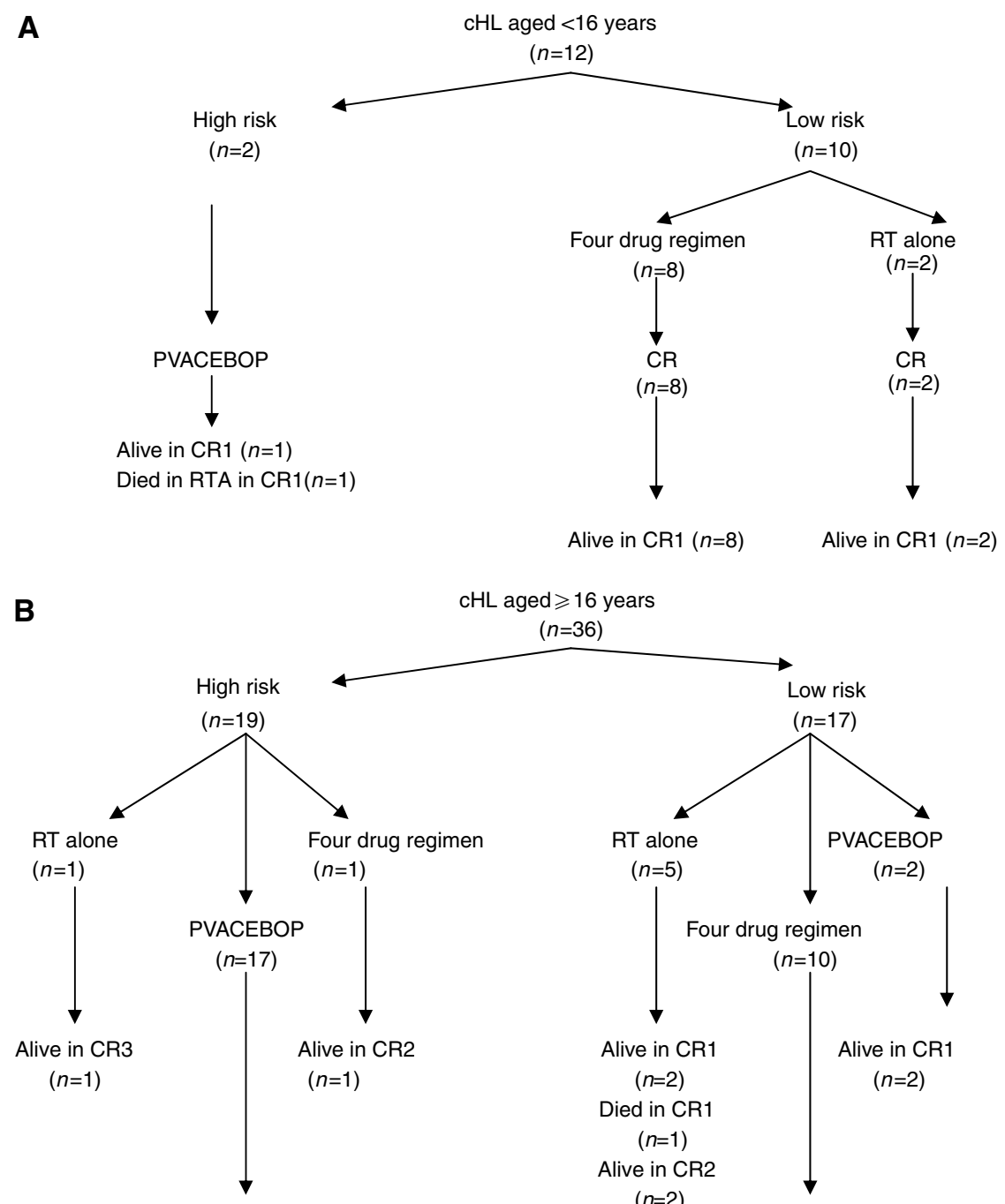

Alive in CR1 $(n=10)$

$\mathrm{L}$ aged $\geqslant 16$ years

Alive in CR2 $(n=3)$

Alive in CR3 $(n=1)$

$(n=36)$

Died of $\mathrm{HL}(n=3)$

Figure 2 (A) Classical HL aged $<16$ years. (B) Classical $H L$ aged $\geqslant 16$ years. 

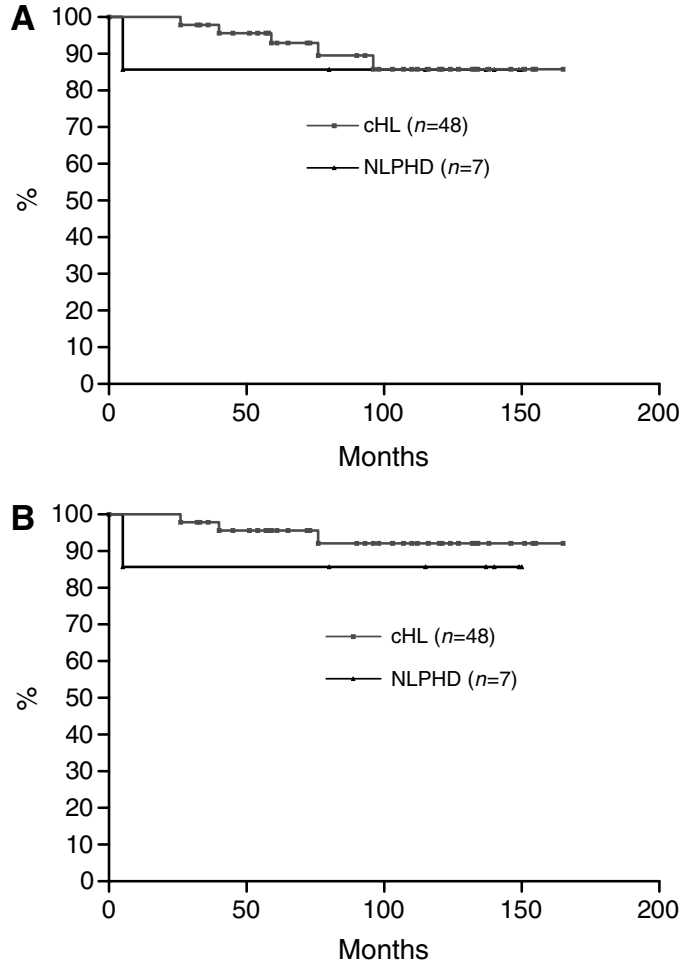

Figure 3 (A) Overall survival. (B) Disease-specific survival (censored for deaths unrelated to $\mathrm{HL}$ )

patients remained in CR1, three patients relapsed but had been salvaged with chemotherapy and were alive in CR. One patient, who also had cystic fibrosis, died 96 months after presentation of disseminated varicella zoster infection.

Compliance with regional protocol As discussed, the SNLG index can only be reliably applied to patients aged $\geqslant 16$ years. With regard to these patients, regional guidelines were followed in 32 out of 36 cases. Two low-indexed patients were treated on the PVACEBOP protocol, one high-indexed patient received ABVD as she could not tolerate oral medication and one high indexed patient received radiotherapy alone.

Comparison of SNLG and Smith prognostic indices The Smith Index (Figure 1B), a prognostic score for childhood HL, was published in 2003 (Smith et al, 2003). It was therefore not available during the period these patients were treated. Nevertheless there is high concordance of Smith scores 3-5 as SNLG high-risk and Smith scores $<3$ as low-risk SNLG . Overall, there is agreement in risk allocation for 31 out of 36 patients. Five individuals were scored as high risk using the SNLG index (Figure 1A) and low risk using the Smith score. Of these patients, one received ABVD due to intolerance of oral medication and relapsed but received successful salvage therapy. Four patients received PVACEBOP-based therapy; two patients relapsed, one of whom had subsequently died of progressive disease. The Hasencleaver index could not be used in this cohort, as the serum albumin estimations had been recorded only in a minority of the cohort.

\section{NLPHL}

This group comprised seven patients, three aged $<16$ years and four aged $\geqslant 16$ years. Therapy comprised radiotherapy alone $(n=3)$, ChlVPP/ABVD + radiotherapy $(n=2), \quad$ ABVD + radiotherapy $(n=1)$ and PVACEBOP + radiotherapy $(n=1)$. Remission was achieved in $6 / 7$ cases. The refractory patient was treated with PVACEBOP, achieved a partial remission but relapsed 4 months later with high-grade non-HL, and died of progressive disease 5 months after diagnosis. Two other patients relapsed but were salvaged with chemotherapy and autologous HSCT.

\section{DISCUSSION}

Hodgkin's lymphoma in patients aged over 15 years was a subject of substantial research interest in the former Northern Region UK from 1982 onwards. This led to the development of the SNLG prognostic index in 1985, and although not published until 1991, it was used prospectively to define risk status as 'standard' or 'high' from 1987 (Proctor et al, 1991). It became the defining element of the SNLG-HD III randomised study for high-risk patients, which ran from 1988 to 1998 (Proctor et al, 2002). As a result, adolescents in the region who developed HL were prospectively assessed as described above, hence the early emergence of the risk - related strategy for the over 16 years cohort described here.

For patients with cHL, the 5-year and 10-year OS for this cohort was 93 and $86 \%$, respectively. Overall survival for patients with early stage (stages IA, IIA) was 100 and $91 \%$, respectively. These results compare favourably with other published studies, which have included adolescent patients (Table 3 ).

It should be borne in mind that, with the exception of the present study and those of Yung et al (2004) and Foltz et al (2006), all of the studies in Table 3 included younger children in addition to adolescents. It is not clear whether the prognosis of HL is the same in young children and teenagers; younger children have a better outcome than adolescents in some (Weiner et al, 1991) but not all studies (Schellong et al, 1999). In their study, specifically investigating adolescents with HL, Yung et al (2004) demonstrated a 5 -year OS of $81 \%$ and EFS of $50 \%$ in a cohort of 210 patients. These patients, aged 15-17 years, were diagnosed from 1970-1997 and were treated according to adult protocols. Based on these data, the authors postulated that adolescents may be best treated using paediatric rather than adult treatment protocols. Survival data presented in our own study, using an adult risk-related approach, are better than those reported by Yung and co-workers. There are clearly several differences between the study of Yung and coworkers and the present study. These need to be considered when comparing results. The present study is population-based, the age range of the patients treated is broader and the patients were treated more recently than those described by Yung and coworkers. There was, however, no difference in survival by decade of treatment in the latter study. The present study describes the use of a risk-adapted treatment strategy and has demonstrated outcomes, which are comparable with those published by a number of paediatric groups (Ekert et al, 1988; Shankar et al, 1998; Schellong et al, 1999; Landmann-Parker et al, 2000; Smith et al, 2003; Oguz et al, 2005).

Recently Foltz et al (2006) have published the population experience of the British Columbia Cancer Agency lymphoid cancer database. The group included 259 individuals aged 1621 yrs treated with adult therapy protocols. Overall survival and progression-free survival at 10 years were 91 and $77 \%$, respectively. These survival data are similar to our own, with 10 -year OS and EFS of 86 and $78 \%$ respectively, and suggest that adolescents can do well when managed using adult protocols.

The possible impact of the population-based nature of the data collected in this series and that of Foltz and co-workers is worthy of consideration. Among older patients with HL, it has been repeatedly demonstrated that the survival data in populationbased studies are poorer than those from clinical trials (Kennedy et al, 1985; Appleton et al, 1995; Clarke et al, 2001; Proctor et al, 2002; Jarrett et al, 2005). This effect is likely to be due, at least in part, to the exclusion of frailer elderly individuals from clinical 
Table 3 Published outcomes for adolescent patients with $\mathrm{HL}$

\begin{tabular}{|c|c|c|c|c|c|c|c|c|c|c|c|}
\hline Authors & $\begin{array}{l}\text { Publication } \\
\text { year }\end{array}$ & $\begin{array}{l}\text { Number of } \\
\text { patients }\end{array}$ & $\begin{array}{c}\text { Ages } \\
\text { (years) }\end{array}$ & $\begin{array}{l}\text { Median age } \\
\text { (years) }\end{array}$ & Stages & $\begin{array}{l}\text { NLPHL } \\
\text { included }\end{array}$ & $\begin{array}{l}\text { Median F/U } \\
\text { (month) }\end{array}$ & CR rate & 5 year os & 5 year EFS & Study type \\
\hline Clarke et al & 2001 & 5630 & $15-44$ & NS & NS & Yes & 53 & NS & NS & 5 year DFS $90 \%$ & Retrospective, population based \\
\hline $\begin{array}{l}\text { Donaldson and } \\
\text { Link }\end{array}$ & 1987 & 55 & $1.5-15$ & 10 & All & Yes & 90 & $93 \%$ & $89 \%$ at 15 years & 5 year RFS 90\% & Prospective, observational \\
\hline Donaldson et al & 2002 & 110 & $3-20$ & 13 & All & Yes & 67 & $100 \%$ & $99 \%$ & $93 \%$ & $\begin{array}{l}\text { Prospective, observational, focused on LR } \\
\text { disease }\end{array}$ \\
\hline Ekert et al & 1988 & 53 & $3-16$ & 10 & All & Yes & 45 & $96 \%$ & $94 \%$ & $92 \%$ & Prospective observational \\
\hline Foltz et al & 2006 & 259 & $|6-2|$ & 19 & All & Yes & 102 & $97 \%$ & $91 \%$ & 10 year PFS $77 \%$ & Prospective observational \\
\hline Friedmann et al & 2002 & 56 & $8-18$ & 15 & All (only HR I-II) & Yes & 108 & $94 \%$ & $82 \%$ & $68 \%$ & $\begin{array}{l}\text { Prospective, observational, focused on HR } \\
\text { disease }\end{array}$ \\
\hline Hudson et al & 1993 & 85 & $4-20$ & 14 & $\| \mathrm{A}-\mathrm{IVB}$ & Yes & 49 & $98 \%$ & $93 \%$ & 5 year DFS 93\% & $\begin{array}{l}\text { Prospective, observational, focused on HR } \\
\text { disease }\end{array}$ \\
\hline Hudson et al & 2004 & 159 & $2-19$ & 15 & All (only HR I-II) & Yes & 70 & NS & $93 \%$ & $76 \%$ & $\begin{array}{l}\text { Prospective, observational, focused on HR } \\
\text { disease }\end{array}$ \\
\hline Hunger et al & 1994 & 57 & $<18$ & 12 & All & Yes & 80 & $100 \%$ & $96 \%$ & $93 \%$ & Prospective, observational \\
\hline Hutchinson & 1998 & 111 & $<21$ & NS & III/IV only & Yes & 74 & NS & $87 \%$ at 4 years & $82 \%$ at 4 years & $R C T$, focused on HR disease \\
\hline Jenkin et al & 1982 & 110 & $<16$ & NS & All & Yes & 70 & NS & $92 \%$ & RFS $68 \%$ & Prospective, observational \\
\hline Jones et al & $\begin{array}{l}\text { Present paper } \\
2007\end{array}$ & 55 & $13-19$ & 16 & All & Yes & 107 & $93 \%$ & $91 \%$ & & Prospective, population-based \\
\hline $\begin{array}{l}\text { Landman- } \\
\text { Parker et al }\end{array}$ & 2000 & 202 & $3-18$ & 12 & |/II only & No & 74 & NS & $98 \%$ & $91 \%$ & $\begin{array}{l}\text { Prospective, observational, risk-adapted } \\
\text { approach }\end{array}$ \\
\hline Nachman et al & 2002 & 829 & $<21$ & NS & All & Yes & NA & $83 \%$ & $95 \%$ at 3 years & $87 \%$ at 3 years & RCT for patients in CR after chemotherapy \\
\hline Oguz et al & 2005 & 65 & $2-15$ & 7 & All & Yes & 73 & $95 \%$ & $96 \%$ & $91 \%$ & Prospective, observational \\
\hline Schellong et al & 1999 & 578 & $2-17$ & 13 & All & Yes & 61 & NS & $98 \%$ & $91 \%$ & Prospective, observational \\
\hline Shanker et al & 1998 & 54 & $2-19$ & 10 & All & Yes & 66 & $76 \%$ & $\begin{array}{l}\text { Stage I-III 93\% } \\
\text { Stage IV } 44 \%\end{array}$ & & Prospective, observational \\
\hline Smith et al & 2003 & 328 & $2-20$ & 14 & All & Yes & 59 & NS & $93 \%$ & DFS at 5 years $83 \%$ & $\begin{array}{l}\text { Prospective, observational using risk- } \\
\text { adapted protocols }\end{array}$ \\
\hline Weiner et al & 1997 & 179 & $4-20$ & 13 & $\geqslant \| B$ & Yes & NS & $90 \%$ & $92 \%$ & $79 \%$ & RCT focused on HR disease \\
\hline Yung et al & 2004 & 210 & $15-17$ & 16 & All & Yes & 199 & $76 \%$ & $81 \%$ & $50 \%$ & Retrospective, observational \\
\hline
\end{tabular}

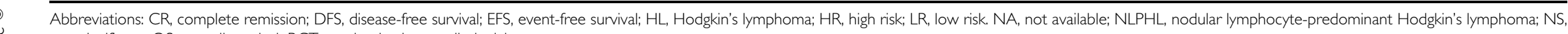
non-significant; OS, overall survival; RCT, randomised controlled trial. 
trials. It is not clear, however, whether a population-based approach may have a different impact in adolescent patients. It is conceivable that young patients with HL and poor prognostic features may enter trials in preference to those with lower-risk disease and indeed many clinical trials focus on those patients with poorer-risk disease (Hudson et al, 1993, 2004; Hutchinson et al, 1998; Friedmann et al, 2002). This may be another explanation of the differences between the present investigation and that of Yung co-workers; most of the patients in the latter study were registered at the time of recruitment to clinical trials.

While several studies (Jenkin et al, 1982; Shankar et al, 1998; Schellong et al, 1999; Oguz et al, 2005; Foltz et al, 2006) stratified patients to receive therapy based on stage of disease at presentation, no group specifically took into account additional prognostic factors such as those that comprise the SNLG index. Given the population-based nature of our study and the age range of patients included, we contend that the survival data presented in this cohort, the small number of patients requiring salvage therapy, and to date lack of secondary malignancy justifies our risk-adapted approach. Using an alternative strategy, LandmannParker et al (2000), stratified patients based on their response to an initial four cycles of chemotherapy. This group studied only patients with early stage disease; the results are similar to our own for patients with IA and IIA disease.

Current and proposed trials are assessing the use of PET scanning during therapy to inform the risk issue on an individual patient during treatment. This approach seems to have much merit as it allows standard or escalated therapy to be introduced according to response. The additional value of such an approach is that fertility might be better preserved in male patients using ABVD alone. Certainly eight-drug schedules, such as PVACEBOP, are associated with inevitable male sterility, although female fertility in the under 40 years patients on SNLG-HD III (Proctor et al, 2002) has been well preserved. We would argue that the new study approaches should be linked to assessment of existing prognostic indices to further assess their role in defining risk.

\section{REFERENCES}

Appleton AL, Sviland L, Peiris JSM, Taylor CE, Wilkes J, Green MA, Pearson ADJ, Kelly PJ, Malcolm AJ, Proctor SJ, Hamilton PJ, Cant AJ (1995) Human herpes virus-6 infection in marrow graft recipients: role in pathogenesis of graft-versus-host disease. Bone Marrow Transplant 16: $777-782$

Armstrong AA, Lennard A, Alexander FE, Angus B, Proctor SJ, Onions DE, Jarrett RF (1994) Prognostic significance of Epstein-Barr virus association in Hodgkin's disease. Eur J Cancer 30A(7): 1045-1046

Clarke CA, Glaser SL, Prehn AW (2001) Age-specific survival after Hodgkin's disease in a population-based cohort (United States). Cancer Causes Control 12: 803-812

Cotterill SJ, Parker L, Malcolm AJ, Reid M, More L, Craft AW (2000) Incidence and survival for cancer in children and young adults in the North of England, 1968 - 1995: a report from the Northern Region Young Person's Malignant Disease Registry. Br J Cancer 83: 397 - 403

Donaldson SS, Link MP (1987) Combined modality treatment with lowdose radiation and MOPP chemotherapy for children with Hodgkin's disease. J Clin Oncol 5: 742-749

Donaldson SS, Hudson MM, Lamborn KR, Link MP, Kun L, Billet AL, Marcus KC, Hurwitz CA, Young JA, Tarbell NJ, Weinstein HJ (2002) VAMP and low-dose involved field radiation for children and adolescents with favourable early-stage Hodgkin's disease: results of a prospective clinical trial. J Clin Oncol 20: 3081 - 3087

Ekert H, Waters KD, Smith PJ, Toogood I, Mauger D (1988) Treatment with MOPP or ChlVPP chemotherapy only for all stages of childhood Hodgkin's disease. J Clin Oncol 6: $1845-1850$

Foltz LM, Song KW, Connors JM (2006) Hodgkin's lymphoma in adolescents. J Clin Oncol 24: 2520-2526

Friedmann AM, Hudson MM, Weinstein HJ, Donaldson SS, Kun L, Tarbell NJ, Link MP (2002) Treatment of unfavourable childhood Hodgkin's
Nodular lymphocyte-predominant HL is now recognised as being a form of low-grade B-cell non-HL rather than a variant of cHL (Stoler et al, 1995; Harris et al, 2000). Several studies, including the small cohort investigated in the present series, have failed to demonstrate a survival difference between patients with NLPHL and those with other forms of the disease (Proctor et al, 1991; Weiner et al, 1991; Hunger et al, 1994). It seems unlikely that inclusion or exclusion of this small proportion of patients from the studies outlined in Table 3 would have a significant impact on overall results.

One of the other major considerations in the treatment of young patients with $\mathrm{HL}$ is the risk of late adverse effects of treatment. In the present study, follow-up is too short to allow an accurate assessment of the late effects of this risk-adapted therapeutic approach, but the results are generally encouraging; no secondary leukaemia or solid tumours have been reported in this cohort to date.

\section{CONCLUSION}

This study demonstrates that a coordinated approach, involving adult and paediatric physicians, and the use of a risk-adapted treatment protocol are effective in the management of $\mathrm{HL}$ in adolescents. Given the relative rarity of $\mathrm{HL}$ in adolescents, a national population-based registry approach could provide valuable information with respect to best practice in addition to providing a vehicle to promote recruitment into clinical trials.

\section{ACKNOWLEDGEMENTS}

We acknowledge oncologists and haematologists in Northern Region for permission to report their patients, the staff of the Scotland and Newcastle Lymphoma Group (SNLG) for data management and Carol Waugh for secretarial support. The study was completed following ethical approval by the Newcastle and North Tyneside Local Research Ethics Committee. disease with VEPA and low-dose, involved-field radiation. J Clin Oncol 20: $3088-3094$

Harris NL, Jaffe ES, Diebold J (2000) The WHO classification of neoplastic disease of the haemopoietic and lymphoid tissues. Histopathology 36: 69-87 Hudson MM, Greenwald C, Thompson E, Wilmas J, Marina N, Fairclough D, Kauffman W, Bozeman P, Mackert PW, Abromowitch M, Jenkins J, Boulden T, Kun L (1993) Efficacy and toxicity of multiagent chemotherapy and low-dose involved-field radiotherapy in children and adolescents with Hodgkin's disease. J Clin Oncol 11: 100-108

Hudson MM, Krasin M, Link MP, Donaldson SS, Billups C, Merchant TE, Kun L, Billet AL, Kaste S, Tarbell NJ, Howard S, Friedmann AM, Hurwitz CA, Young JA, Marcus KC, Rai S, Cowan T, Weinstein HJ (2004) Risk-adapted, combined-modality therapy with VAMP/COP and response-based, involved-field radiation for unfavourable pediatric Hodgkin's disease. J Clin Oncol 22: $4541-4550$

Hunger SP, Link MP, Donaldson SS (1994) ABVD/MOPP and low-dose involved-field radiotherapy in pediatric Hodgkin's disease: the Stanford experience. J Clin Oncol 12: 2160-2166

Hutchinson RJ, Fryer CJH, Davis PC, Nachman J, Krailo MD, O’Brien RT, Collins RD, Whalen T, Reardon D, Trigg ME, Gilchrist GS (1998) MOPP or radiation in addition to ABVD in the treatment of pathologically staged advanced Hodgkin's disease in children: results of the Children's Cancer Group phase III trial. J Clin Oncol 16: 897-906

Jarrett RF, Stark GL, White J, Angus B, Alexander FE, Krajewski AS, Freeland J, Taylor GM, Taylor PRA (2005) Impact of tumor Epstein - Barr virus status on presenting features and outcome in age-defined subgroups of patients with classic Hodgkin lymphoma: a populationbased study. Blood 106: 2444-2451

Jenkin D, Chan H, Freedman M, Greenberg M, Gribbin M, McClure P, Saunders F, Sonley M (1982) Hodgkin's disease in children: treatment 
results with MOPP and low-dose extended-field irradiation. Cancer Treat Rep 66: $949-959$

Kaplan EL, Meier P (1958) Non-parametric estimation from incomplete observations. J Am Stat Assoc 53: 457-481

Keegan THM, Glaser SL, Clarke CA, Gulley ML, Craig FE, DiGuiseppe JA, Dorfman RF, Mann RB, Ambinder RF (2005) Epstein-Barr virus as a marker of survival after Hodgkin's lymphoma: a population-based study. J Clin Oncol 23: 7604-7613

Kennedy BJ, Loeb V, Peterson VM, Donegan WL, Natarajan N, Mettlin C (1985) National survey of patterns of care for Hodgkin's disease. Cancer 56: $2547-2556$

Landmann-Parker J, Pacquement H, Leblanc T, Habrand HJ, TerrierLacombe MJ, Bertrand Y, Perel Y, Robert A, Coze C, Thuret I, Donadieu J, Schaison G, Leverger G, Lemerle J, Oberlin O (2000) Localized childhood Hodgkin's disease: response-adapted chemotherapy with etoposide, bleomycin, vinblastine and prednisone before low-dose radiation therapy - results of the French Society for Pediatric Oncology Study MDH90. J Clin Oncol 18: 1500-1507

Nachman JB, Sposto R, Herzog P, Gilchrist GS, Wolden SL, Thimson J, Kadin ME, Pattengale P, Davis PC, Hutchinson RJ, White K (2002) Randomized comparison of low-dose involved-field radiotherapy and no radiotherapy for children with Hodgkin's disease who achieve a complete response to chemotherapy. J Clin Oncol 20: 3765-3771

Oguz A, Karadeniz C, Okur FV, Citak EC, Pinarl FG, Bora H, Akyurek N (2005) Prognostic factors and treatment outcome in childhood Hodgkin disease. Pediatr Blood Cancer 45: 670-675

Proctor SJ, Mackie M, Dawson A, White J, Prescott RJ, Lucraft HL, Angus B, Jackson GH, Lennard AL, Hepplestone A, Taylor PRA (2002) A population-based study of intensive multi-agent chemotherapy with or without autotransplant for the highest risk Hodgkins disease patients identified by the Scotland and Newcastle Lymphoma Group prognostic index. Eur J Cancer 38: 795-806

Proctor SJ, Taylor P, Donnan P, Boys R, Lennard A, Prescott RJ (1991) A numerical prognostic index for clinical use in identification of poor-risk patients with Hodgkin's disease at diagnosis. Eur J Cancer 27: 624-629

Schellong G, Potter R, Bramswig J, Wagner W, Prott F, Dorfell W, Korholz D, Mann G, Rath B, Reiter A, Weissbach G, Riepenhausen M, Thiemann
M, Schwarze E (1999) High cure rates and reduced long-term toxicity in pediatric Hodgkin's disease: the German-Austrian Multicenter Trial DAL-HD-90. J Clin Oncol 17: 3736-3744

Shankar AG, Ashley S, Atra A, Kingston JE, Mott M, Pinkerton CR (1998) A limited role for VEEP (vincristine, etoposide, epirubicin, prednisolone) chemotherpay in childhood Hodgkin's disease. Eur J Cancer 34: 2058 - 2063 Shankar AG, Ashley S, Radford M, Barrett A, Wright DH, Pinkerton CR (1997) Does histology influence outcome in childhood Hodgkin's disease? Results from the United Kingdom Children's Cancer Study Group. J Clin Oncol 15: 2622-2630

Smith RS, Chen Q, Hudson MM, Link MP, Kun L, Weinstein H, Billet A, Marcus KJ, Tarbell NJ, Donaldson SS (2003) Prognostic factors for children with Hodgkin's disease treated with combined-modality therapy. J Clin Oncol 21: 2026-2033

Stoler MH, Nichols GE, Symbula M, Weiss LM (1995) Lymphocyte predominance Hodgkin's disease. Evidence for a kappa light chainrestricted monocytic B-cell neoplasm. Am J Pathol 146: 812-818

Taylor PRA, Angus B, Owen JP, Proctor SJ (1998) Hodgkin's disease: a population-adjusted clinical epidemiological study (PACE) of management at presentation. QJM 91: $131-139$

Weiner MA, Levanthal BG, Marcus R (1991) Intensive chemotherapy and low-dose radiotherapy for the treatment of asvanced stage Hodgkin's disease in pediatric patients: a Pediatric Oncology Group Study. J Clin Oncol 9: $1591-1598$

Weiner MA, Leventhal B, Brecher ML, Marcus RB, Cantor A, Gieser PW, Ternberg JL, Behm FG, Wharam MD, Chauvet AR (1997) Randomized study of intensive MOPP-ABVD with or without low-dose tota-nodal radiation therapy in the treatment of stages IIB, IIIA2 and IV Hodgkin's disease in pediatric patients: a Pediatric Oncology Group Study. J Clin Oncol 15: $2769-2779$

Windebank KP. (2005) Hodgkin's disease and adolescents: the lost tribe. In: Eden TOB, Barr RD, Bleyer A, Whiteson M (eds). Cancer and the Adolescent. Oxford: Blackwell Publishing

Yung L, Smith P, Hancock BW, Hoskin P, Gilson D, Vernon C, Linch DC (2004) Long term outcome in adolescents with Hodgkin's lymphoma: poor results using regimens designed for adults. Leuk Lymphoma 45: $1579-1585$ 